This paper has been published in Tourism and Hospitality Research (2009) vol. 9, no. 4, 290-304. When citing, please consult the final published version.

\title{
Holidaying with the family pet: No dogs allowed!
}

\section{Dr. Neil Carr}

University of Otago, New Zealand

Dr. Scott Cohen ${ }^{1}$

University of Otago, New Zealand

Department of Tourism

University of Otago

$4^{\text {th }}$ Floor, Commerce Building

P.O Box 56

Dunedin

New Zealand

Tel: + 6434795048

Fax: + 6434799034

Email: ncarr@business.otago.ac.nz

${ }^{1}$ present address at School of Tourism, Bournemouth University, United Kingdom

\begin{abstract}
This paper assesses the extent to which dog owners located in Brisbane, Australia wish to holiday with their pets and if there is a gap between this desire and reality. The paper also examines the extent to which this demand is being catered for by the tourism accommodation sector. The need for this study reflects the increasingly significant role dogs are playing in the lives of humans and the scale of the dog owning population.
\end{abstract}

The results suggest whilst there is a strong desire amongst dog owners to take holidays with their pets the actualisation of this desire is comparatively low. A significant obstacle to the realisation of this desire appears to be a dearth of pet friendly accommodation. This has implications for the ability of the tourism industry to benefit from the potentially lucrative market that is the dog-owning population.

Keywords: Dogs; pets; accommodation. 


\section{Introduction}

Pet dogs are playing an ever more significant role in the lives of humans as close companions that breaks the traditional view of human-animal relations. The result is that dogs have become a part of the family in a way that provides companionship, friendship, love, and affection for their human counterparts (Frohlich 2002; Salmon \& Salmon 1983). Indeed, Racher (2005: 11) states that "dogs have become a major element of many families.”

As part of the breaking down of the traditional notions of human-animal relations it has been recognised that people may gain a variety of psychological and health benefits from the human-dog relationship and the time both sides spend together (McHarg et al. 1995; Bauman et al. 2001; Rogers \& Hart, 1993; Petnet.com 2000a). It has been claimed that these benefits result in pet owners making fewer visits to doctors and hospital than their non-pet owning counterparts (Headey, 1998). In particular dog ownership has been linked with lower blood pressure and a reduced risk of heart attacks and strokes (Anderson, et al., 1992). The social benefits of dog ownership are also numerous as they often play the role of 'social facilitator' for their owners (Blackshaw \& Marriott 1995; Messent 1983). In addition to humans benefiting from contact with dogs, it has been noted that dogs gain health and psychological benefits from spending time with their owners (Becks \& Katcher, 2003) and are less likely to develop antisocial behaviours as a result of this contact. Therefore, holidaying with dogs may have a variety of benefits for owners and their pets. However, the traditional image of pets at the time of the family vacation is not one of the animal and its human owners spending time together but of animals in general and dogs in particular being left behind with friends/relatives or in kennels (CNN, 2006; Meddaugh, 1994). The apparent importance to dogs and their owners of spending time together makes investigation of the desire and ability of people to take their pets on holiday with them an important area of investigation.

Despite the potential importance of pet dogs and their human owners holidaying together there is a dearth of analysis on the topic of pet tourism in general and pet-dog 
tourism in particular. This situation may reflect a general tendency in modern societies and tourism studies to view animals as objects to be consumed rather than living beings and, alongside their human companions, potential consumers who are able to influence decision making processes. Indeed, within tourism studies the traditional focus has been on studying animals that live in the holiday environment and are part of the tourist attraction (e.g., Hughes, et al., 2005; Mainini, et al., 1993; Curtin, 2005) rather than as potential consumers themselves and/or influences on their human companions' consumption of the tourism experience. As part of this process the focus has been on the exotic 'other' rather than on domesticated pets such as the dog. This reflects a wider reality across academia that most domesticated animals and pets, including the dog, are less researched and understood than a wide array of wild animals (Csanyi, 2005). Consequently, although a significant proportion of the work that has been conducted on animals in the tourism environment has been concerned with the rights and well being of these creatures it is limited in that it has only been concerned with animals that exist within holiday locations and has yet to address the needs of animals visiting these areas and/or their human companions.

The figures for dog ownership and spending on these animals by their owners suggest these people have the potential to be a lucrative revenue stream in the tourism market (Frohlich 2002). Indeed, within Australia it was estimated in 2002 that there were $3,972,000$ pet dogs spread across approximately $37 \%$ of the households in the country (Petnet.com. 2003). In comparison, 36\% of American households were identified as owning at least one dog in 2003 (Pet Food Institute, 2006). Furthermore, it appears that the presence of dogs in households is an increasingly common situation. For example, Figure 1 shows that the number of households that own at least one pet dog in the USA increased by $5 \%$ between 1981 and 2003. Within Australia the current dog owning population appears to have the potential to grow significantly with over $50 \%$ of non-pet owning Australian households stating they would like to have a pet in the future and $80 \%$ of them identifying a dog as their pet of choice (McHarg et al. 1995).

As a result of their numbers dogs represent a significant component of the multi-billion dollar pet care industry that now exists around the globe. Within the context of Australia 
this industry was worth $\$ 2.3$ billion in 2003 (Denniss, 2004). Of the total spent on pets annually in Australia approximately 60\% is accounted for by dogs (Petnet.com, 2007). In addition, it is increasingly recognised that spending on pets in general and dogs in particular is no longer restricted to catering for the animals' basic needs but encompasses significant spending on a range of items previously defined as nonessential. Indeed, of the estimated US\$2.1 trillion spent by Americans on their leisure pursuits in 2006, US\$38 billion was associated with their pets (Miller, 2006). Similarly, within Australia 3.6\% of the total household recreation expenditure according to the Australian Bureau of Statistics (2000 in Veal \& Lynch, 2001) was spent on pets.

Another indication of the potential scale of the demand for dog friendly holidays is provided by the Pet Travel Scheme that was introduced in 1999 in the UK to allow pets, including dogs, from certain countries to enter the UK without having to go into quarantine (Newton, 1999). It was estimated by the British Tourism Authority that this scheme would result in 1.7 million pets, mostly dogs, joining their owners on holiday to the UK from France and Germany (Golding 1999). In addition, in 2003 Canada developed the first nationally recognized pet-friendly tourist accommodation certification program based on the recognition that people who wish to holiday with their pets represent the fastest growing niche market in tourism (Canadian Tourism Commission, 2003). Further evidence of the expanding demand for dog-friendly tourism experiences was provided in a study by the American Pet Products Manufacturers Association published by Travelwire News (2005) that indicated in the USA leisure-oriented pet air travel "soared 33 percent last year [2004] to a record 20 million [pets flying with their owners].... and 80 percent of them were dogs." Yet despite these figures no research has been conducted to date to assess the scale of the dog owning population who take/wish to take their pets on holiday with them.

In recognition of the changing nature of the human-dog relationship and the potential value of dog friendly holidays to accommodation providers a variety of hotels, primarily in North-western Europe and North America, are beginning to actively encourage guests to bring their dogs on holiday with them. For example, in France the Versailles' Trianon Palace announced in 2003 that it intended to allow dogs to stay in their owners' rooms 
and would offer four-legged guests an agility course (Henley 2003). In addition, Starwood Hotels and Resorts Worldwide, Inc, based in the USA, has pledged to become the most dog-friendly hotel company in the world (Sakakeeny 2004). Despite these developments there has been a lack of analysis of the demand for and access to accommodation units for pet-dogs and their human companions.

Based on the scale of the pet dog population and the benefits to be gained from owners and dogs spending their leisure time together for both humans and their pets, the aim of this paper is to assess the extent to which dog owners wish to holiday with their pets and the reality of their holiday experiences. In addition, the paper examines the extent to which dog owners perceive the demand for dog friendly holiday accommodation is being catered for by the tourism industry. The focus on the provision of pet-friendly accommodation is based on the recognition that in the context of the tourism experience the provision of appropriate accommodation is key to the actualisation of potential market demand.

\section{Methodology}

The data required to assess the holiday experiences and desires of dog owners was collected using a questionnaire survey that incorporated a mixture of open and closed questions. The decision to utilise this data collection method was based on the recognition that it enables the gathering of a relatively large amount of data in a quick and efficient manner (Hartmann, 1988; Jennings, 2001). A pilot test of the survey was undertaken in February 2004 to ensure potential respondents understood what the questions were asking and could complete the survey without the need for additional information. The survey was distributed to a convenience sample of 311 dog owners living in Brisbane, Australia between March and June of 2004. The dog owners were approached by two research assistants, one male and one female, at 11 off-leash dog parks and 1 dog friendly beach (as defined by the city council) located around the city. These data collection sites represent a convenience sample of the off-leash parks and dog friendly beaches that exist within the Brisbane city limits. The decision to locate the data collection process where dog owners are able to freely exercise their pets was 
based on the understanding that these areas act as social venues for dog owners (Blackshaw \& Marriott 1995). Consequently, the owners were likely to be relaxed whilst in these areas and therefore more willing to partake in the study. The validity of this hypothesis appears to have been confirmed by the relatively high response rate $(85 \%)$ for this study. In addition to the usual questions about the representativeness of convenience samples it is recognised that the users of off-leash parks and dog-friendly beaches may not be representative of dog owners as a whole. Therefore, rather than examining dog owners as a general population, this study may be more accurately defined as a study of dog owners who frequent off-leash areas.

The characteristics of the respondents and their dogs are outlined in Table 1 which shows that the majority of respondents were married/co-habiting, did not have children, and were between 26 and 45 years old. Where respondents indicated they owned more than one $\operatorname{dog}(30.6 \%$ of the sample) the size of the largest dog they owned is indicated in Table 1 as it was hypothesised that if size of dog had an impact on dog owners holiday experiences it was most likely to be the largest dogs that had the most significant impact. Table 1 shows that dogs that are 22 inches and higher were the most commonly owned by respondents. This group includes dogs such as Labradors, German Shepherds, and Rhodesian Ridgebacks (dogsindepth.com, 2007).

A content analysis of five websites (dogs4sale.com.au, doggyholiday.com, holidayingwithdogs.com.au, petsplayground.com.au, and takeabreak.com.au) and two guidebooks (Australian dogs on holiday and Holidaying with dogs) dedicated to advertising self-defined dog friendly accommodation in Australia was undertaken in January 2005 to identify the extent and nature of this type of accommodation. These sources represented all of the major websites and guidebooks advertising dog friendly holiday lodgings in Australia. The content analysis examined the types of accommodation advertised as being dog-friendly and the nature of any restrictions imposed by accommodation providers on visitors and their dogs.

\section{Data Analysis}


Only $4.2 \%$ of the respondents stated they preferred not to take their dog on holiday with them. However, these people generally stressed that their pet was happy to be left behind. For example, one respondent who owned a Labrador-Kelpie cross stated "We do not take our dog on holidays with us. He goes to his friend's house during this time. He has a great time with the other dog for company." Similarly, the owner of a Miniature Schnauzer said "I never take the dog on holidays. He thoroughly enjoys staying with one particular friend."

In contrast, the other 298 respondents provided, as shown in Table 2, a variety of reasons to explain why they preferred to take their pets on holidays with them. One of the most popular reasons for taking a dog on holiday expressed by the owners was that it was a 'member of the family', which often included the dog being likened to a child. This finding is similar to the results of a study of dog owners in the USA that found $78 \%$ of respondents considered their dog to be an 'equal member' of their family (Hotel Online 2003). In addition, respondents stated that their dog offered enjoyable companionship and was frequently referred to as the owners' best friend so should not be left at home while the owner went on holiday. A high proportion of the owners' who stated they preferred to take their dog on holiday with them also felt that the presence of their dog in the holiday environment added to the pleasure, enjoyment, and relaxation gained by them from the vacation experience. As shown in Table 2, eighteen of the respondents also stated that taking their dog on holiday with them allowed the owners to avoid feeling guilty about enjoying themselves while their pet was left at home or in a kennel.

It is interesting to note that the majority of the reasons given by the respondents to explain their desire to take their $\mathrm{dog} / \mathrm{s}$ on holiday with them are oriented towards increasing the owners' enjoyment of the holiday experience. In contrast, relatively few of the respondents identified their desire to take their pet on holiday with a wish to benefit their $\mathrm{dog} / \mathrm{s}$. The most commonly given pet-oriented explanation for taking dogs on holiday was to 'make the dog happy' whilst 15 respondents also stated that by taking their pet on holiday it would not suffer from depression or anxiety as a result of being separated from its owners. Similarly, a study in the USA found that owners felt that 
their dogs may be depressed if left behind whilst the rest of the family went on holiday. However, the level of this perception was far higher level (43\% of respondents) in the USA study than in the case of the Australian sample studied in this paper (Hotel Online 2003).

Overall, the desire to take a dog on vacation was summed up by the owner of a KelpieCattle dog cross who stated he/she preferred to take their dog on holiday with them because: "I greatly enjoy spending time with my dog. She enhances my experience of my leisure time in parks, on beaches and with friends. She is entertaining and inspires me to be active and playful. She is great company too and I feel lonely for her - miss her - when I'm away from her for over $24 \mathrm{hrs}$. I also have a responsibility to spend time with my dog - for her happiness and because she is better behaved and trained after leisure time with me." More simplistically, one owners' stated reason for wishing to take his/her Siberian Husky on holiday was that "I just love being with my dog."

Despite the fact that only 13 respondents stated they preferred not to take their dog on holiday with them whilst the other respondents gave a number of reasons why they would prefer to holiday with their pets, the data highlighted in Table 3 shows that dogs were frequently left behind when the owners who took part in this study went on holiday between 1999 and 2004. Even in the case of holidays within Queensland, where the study was located, only $25.7 \%$ of the respondents stated they always took their dog with them. Outside of the state this number fell to just under $10 \%$ in the case of Victoria and New South Wales. When the owners holidayed in either Tasmania or the Northern Territory the number who always took their dogs with them dropped to almost $1 \%$. Overall, the results highlighted in Table 3 show that most dogs were never taken on holidays outside of Queensland and that even on intra-state vacations over one quarter of the owners always left their dogs behind. This suggests there is a significant distance decay effect in terms of the frequency with which dogs are taken on holiday with their owners. This may be due to difficulties associated with travelling with pets over extended distances, especially where air transport is necessary. 
The results shown in Table 3 are similar to those of a study conducted by Newspoll that claimed only $14 \%$ of Australians always take their pet with them on weekend holidays (Petnet.com 2000b). These results contrast with the claim that in the USA $66 \%$ of owners take their pets with them on holiday and $46 \%$ plan all or most of their free time around their pet/s (Kimel 2003). When the data shown in Tables 2 and 3 are compared there appears to be a significant difference between the stated preferred behaviour of the dog owners studied, which is to take their pet on holiday with them, and their actual behaviour, which seems to entail not taking the dog on holiday with them.

A series of chi square tests were conducted utilising the Queensland data highlighted in Table 3 to assess whether there was any difference amongst the survey respondents when they were divided according to their age $\left(\chi^{2}=24.116, \rho=0.002\right)$, marital status $\left(\chi^{2}=14.546, \rho=0.006\right)$, whether they had children $\left(\chi^{2}=5.904, \rho=0.206\right)$, how long they had owned a dog for $\left(\chi^{2}=13.539, \rho=0.331\right)$, the size of their $\operatorname{dog} / \mathrm{s}\left(\chi^{2}=6.273, \rho\right.$ $=0.617)$, and annual household income $\left(\chi^{2}=24.498, \rho=0.433\right)$. The results of these tests indicate there is a significant difference between how frequently the dog owners reported having taken their pet on vacation with them in Queensland when they were divided according to their age and marital status. The results highlighted in Table 4 show that single respondents were more likely than married/co-habiting respondents to report having always taken their dog/s on holiday with them in Queensland. In contrast, the married/co-habiting respondents were more likely never to have taken their $\mathrm{dog} / \mathrm{s}$ on holiday within the State. Table 5 shows that middle-aged (26 to 45 years old) respondents were the least likely to report having always taken their dog/s on holiday in Queensland whereas those under 26 years of age were the most likely to have done so.

A potential explanation for the apparent gap between the desire to take dogs on holiday and actually doing so was offered by several of the respondents. For example, one owner of 2 border collies stated "I would love if they could come on holidays with me." This comment indicates the existence of a constraint that was preventing the owner from engaging in his/her preferred behaviour. Similarly, the owner of an Airedale and Schnauzer stated "it would be nice to have more options to take them along." This statement suggests there is a lack of provision for dog owners to actualise their preferred 
holiday behaviour that is to take their pet with them. This view is supported by the owners of a Labrador and King Charles spaniel who stated they "don't take the dogs with us if going away for the weekend as facilities for them are limited. It is difficult to leave them if going out for a meal etc." Similarly, the owner of a Golden RetrieverSamoyed cross stated whilst their dog was an integral part of the family and that they would like to take it on holiday "unfortunately holiday destinations [that allow dogs] are hard to find." The difficulty associated with finding dog friendly tourism and leisure facilities had even led the owner of two Labradors who had recently emigrated from the UK to state that "we have felt we might have been better leaving the dogs there [in the UK]." It therefore appears that there is a lack of provision for dog owners to actualise their preferred holiday behaviour (i.e., to take their pet with them).

Combined with the comments from the dog owners the results highlighted in Table 6 suggest that one of the reasons why people are not taking their pets on holiday with them may be because it is generally very difficult to find accommodation that is willing to accept the presence of a dog. The data in Table 6 shows that only a relatively small percentage of the respondents found it 'very easy' to locate dog friendly accommodation, irrespective of the type sought. In contrast, the most common response from the dog owners was that it was 'extremely hard' to find any dog friendly accommodation. A significant difference was found between the ease with which respondents reported being able to find dog-friendly holiday accommodation in rural, beach, and urban locations $\left(\chi^{2}=29.833, \rho=0.003\right)$. The data presented in Table 6 indicates that the respondents felt it was hardest to find this type of accommodation in urban areas and easiest in rural locations. A significant difference was also found between the ease with which dog owners stated they could locate budget, mid-price and luxury pet-friendly accommodation $\left(\chi^{2}=23.385, \rho=0.025\right)$. Table 6 shows that the budget accommodation was reported as being the least difficult to find whilst the majority of respondents stated it was extremely hard to locate luxury dog-friendly accommodation. In addition, a significant difference was found between the reported ease with which respondents managed to locate camping, self-catered, and catered accommodation $\left(\chi^{2}=30.678, \rho=0.002\right)$. As the data in Table 6 demonstrates, the latter 
accommodation type was viewed as being the most difficult to find by respondents whilst camping accommodation was felt to be the least difficult to locate.

In addition to preventing people taking pets on holiday with them, a lack of accommodation willing to take their dogs may be preventing dog owners from going on holiday at all, a view supported by Frohlich (2002). For example, the owner of two German shepherd crosses stated "Our dogs are very old (both greater than 13 years). We no longer go away for holidays as we can't leave them in care." Similarly, the owner of a Maltese stated "I haven't been on holidays, as I would have to leave my dog somewhere!"

The problem of finding accommodation that is willing to accept dogs is potentially exacerbated by the lack of high quality information about this type of accommodation from traditional formal sources of holiday material. Indeed, the results highlighted in Table 7 show that only a relatively small percentage of the respondents rated travel agents, tourist information centres, television/radio, or newspapers/magazines as 'very useful' sources of information about dog friendly holiday accommodation. In contrast, between approximately one quarter and one third of the dog owners suggested these sources were 'no use at all' for finding out about dog friendly holiday lodgings. Instead, the two most useful sources of information about pet-friendly holiday accommodation, according to the dog owners, were the Internet and friends $(39.0 \%$ and $48.5 \%$ of respondents ranked these information sources as 'very useful', respectively). The results of a chi square test indicate the differences illustrated in Table 7 are significant $\left(\chi^{2}=\right.$ $492.489, \rho=0.000$ ). Whilst the position of friends as the most useful source of holiday information is common to general studies of tourism holiday decision making processes (Swarbrooke \& Horner, 1999; Carr, 2003) a heavy reliance on this type of information may inhibit the potential for new accommodation units and destinations that are dog friendly to be discovered. However, the Internet provides the potential for new accommodation units and destinations to be explored that are beyond the awareness of friends, which may increase the access of owners to dog friendly holidays. 
Whilst the Internet is potentially useful to dog owners there is still relatively little information about dog friendly accommodation actually on it or elsewhere. Indeed, the search of websites and guidebooks that advertise dog friendly tourism accommodation in Australia conducted as part of the study on which this paper is based found that there were only 2143 units spread throughout the country. Only $4.58 \%$ of these units were identified as hotels whilst the rest were labelled as bed and breakfast units (13.59\%), campsites (42.97\%), self-catering units (26.20\%), or mixed campsite and self-catering units $(12.66 \%)$. This shows a strong bias towards campsites amongst the total of dogfriendly accommodation units available in Australia. These findings mirror the view of the respondents that dog friendly campsites are easier to find than self-catered or catered accommodation units in Australia.

Furthermore, amongst the 1883 units that provided information about how dog friendly they were it is important to note that a significant proportion imposed restrictions/conditions that ranged from not allowing dogs into the accommodation (42.8\%), allowing dogs only at the manager's discretion (36.6\%), allowing dogs only during off-season periods $(2.2 \%)$, to good behaviour bonds $(2.1 \%)$. The limited nature of the extent of some of the units 'dog friendliness' is exemplified in the advert provided by a campsite in Victoria that stated dogs were only allowed "at managements' discretion, not allowed in onsite accommodation or amenities, not allowed at all during peak periods, must be on leash, \& not left unattended" (Doggy Holiday, 2005). In contrast, only $22.3 \%$ of all the self-defined dog friendly accommodation units imposed no restrictions at all or went as far as to say "I get pampered!! When we arrive, a comfy bed is waiting for me beside the wood fire, with my own special towels, shiny bowls and yummy treats. Outside is my own private courtyard complete with a well appointed kennel, just in case I want to catch up on some sleep while my parents go out" as in the case of the Blue Johanna cottages in Victoria (Holidaying With Dogs, 2005). The restricted number of dog friendly accommodation units advertised on the Internet and in guidebooks has the potential to restrict access to holiday experiences for owners who wish to take their dogs with them through a combination of accommodation being unavailable due to demand, limited 
choice of types of accommodation, and not being situated in locations where owners wish to take their vacations.

Faced with the difficulty of finding dog friendly accommodation to enable the realisation of the majority of owners' desires to take their pet on holiday with them it is not be surprising to see that $82.9 \%$ of the respondents, as shown in Table 8 , stated they had had to compromise their holiday desires in order to be able to take their dog with them on vacation. In addition, $16.7 \%$ of the respondents stated it had been necessary for them to totally alter their holiday desires in order to accommodate their dog. The results of a series of chi square tests show that there is no significant difference between the respondents, in terms of how much they had had to compromise their holiday desires in order to take their pets with them, when they were divided according to their age $\left(\chi^{2}=\right.$ 13.777, $\rho=0.088)$, marital status $\left(\chi^{2}=3.813, \rho=0.432\right)$, whether they had children $\left(\chi^{2}\right.$ $=4.283, \rho=0.369)$, how long they had owned a dog for $\left(\chi^{2}=19.934, \rho=0.068\right)$, the size of the $\mathrm{dog} / \mathrm{s}$ they owned $\left(\chi^{2}=7.027, \rho=0.534\right)$, and their annual household income $\left(\chi^{2}=24.809, \rho=0.416\right)$.

As table 8 indicates, despite having to compromise their holiday desires a high percentage of owners were happy to do so. This is important as it supports the concept that the dog has become an integral part of the family (Frohlich 2002) and shows the strength of the owners' desire to take their pets on holiday with them. Indeed, only $12.2 \%$ of the sample stated they were 'not at all' happy to have to compromise their desires in order to be able to take their dog on holiday with them. However, it is important to note that only $21.6 \%$ of the dog owners were totally happy with having to compromise their holiday desires in order to take their pets on vacation with them. The results of a series of chi square tests show that there is no significant difference between the respondents, in terms of how happy they were to compromise their holiday desires in order to take their pets with them, when they were divided according to their age $\left(\chi^{2}\right.$ $=13.680, \rho=0.090)$, marital status $\left(\chi^{2}=3.970, \rho=0.410\right)$, whether they had children $\left(\chi^{2}=8.665, \rho=0.070\right)$, how long they had owned a dog for $\left(\chi^{2}=10.930, \rho=0.535\right)$, the size of the $\operatorname{dog} / \mathrm{s}$ they owned $\left(\chi^{2}=7.490, \rho=0.485\right)$, and their annual household income $\left(\chi^{2}=35.963, \rho=0.055\right)$. 
Figure 2 is based on the $87.1 \%$ of the sample who provided a response when asked 'how much more would you be willing to spend to take your dog on a holiday with you compared to the cost of a holiday without your dog/s.' Figure 2 shows that $27.7 \%$ of respondents stated they would be willing to pay between 6 and $10 \%$ of the cost of holidays that did not include pets in order to take their dogs with them. At the opposite end of the scale $13.3 \%$ of the respondents said that they would be willing to pay more than $25 \%$ of the cost of holidays without pets in order to take their animal on vacation with them. The results of a series of Chi Square tests indicate there is no significant difference between the respondents, in terms of how much they were willing to spend to take their $\mathrm{dog} / \mathrm{s}$ on holiday with them, when they were divided according to their age $\left(\chi^{2}\right.$ $=9.520, \rho=0.484)$, marital status $\left(\chi^{2}=5.818, \rho=0.324\right)$, whether they had children $\left(\chi^{2}=2.132, \rho=0.831\right)$, how long they had owned a dog for $\left(\chi^{2}=10.637, \rho=0.778\right)$, the size of the $\operatorname{dog} / \mathrm{s}$ they owned $\left(\chi^{2}=8.168, \rho=0.417\right)$, and their annual household income $\left(\chi^{2}=34.175, \rho=0.274\right)$.

From the perspective of the tourism industry the results highlighted in Figure 2, when combined with the high level of dog ownership in Australia and the fact that as shown in Table $141.9 \%$ of the respondents reported having an annual household income of more than AUS\$80,000, indicates the existence of a potentially lucrative market that, based on the data shown in this paper, has yet to be catered for. Furthermore, even amongst the accommodation units catering for those seeking pet friendly vacations only $0.85 \%$ of those identified through the guidebook and Internet search conducted as part of the study on which this paper is based stated that they charged for pets to stay in their units. This indicates a further lack of appreciation of the economic potential of providing pet friendly holiday accommodation within the Australian context.

\section{Conclusion}

The results highlighted in this paper show that whilst the desire to take holidays with their pets may be high amongst dog owners in Australia the actualisation of this desire is comparatively low. From the perspective of the dog owners one of the main obstacles 
to the realisation of their wish to holiday with their pets appears to be the difficulty of finding pet friendly accommodation. This issue is not helped by the apparently small number of pet friendly holiday accommodation units in Australia. The result of a lack of dog friendly accommodation and the bias of this type of unit towards campsites and self-catering accommodation means that dog owners have to compromise their holiday desires in order to take their pets on vacation with them.

The difference between the high level of desire amongst dog owners to take their pets on vacation with them and the small percentage of people who actually do this indicates the potential existence of a gap in the tourism industry. The significant size of the dog owning population, even with the recognition that owners who frequent off-leash areas may not be representative of all dog owners, the apparently high desire to of this group to take their pets on holiday with them, and their willingness to pay additional accommodation costs in order to be able to do so all suggests that the dog owning population could represent a significant and lucrative tourism market.

Therefore, the results of this study suggest that the tourism industry in Australia should explore how to provide dog friendly holiday accommodation on a far larger scale than is currently available. There is also a need to expand this type of provision into hotels of all standards as has recently begun to occur in parts of Western Europe and North America. This need is related to the recognition that just as in the case of the general tourist population, not all dog owners may wish to take holidays in self-catering, Bed and Breakfast accommodation, or on campsites.

Further research is required to identify why it appears that the tourism industry in Australia has to date generally failed to provide appropriate accommodation options to dog owners wishing to holiday with their pets. Three potential answers need to be explored as they require different solutions to enable the realisation of the demand for dog-friendly holiday experiences. Firstly, it may be the case that the holiday accommodation sector is unaware of the potential of providing for people wishing to take their dogs on holiday with them. Alternatively, there may be a form of discrimination occurring which bars dog owners from accommodation units. Thirdly, 
accommodation providers may perceive other obstacles to pet-friendly holiday experiences that are beyond their control and will negate the demand of the dog owning tourist population irrespective of the supply of pet-friendly accommodation.

In order to determine the role of these potential explanations in the construction of the current situation regarding dog-friendly holiday accommodation research is needed to assess holiday accommodation operators' perspectives regarding the implications of the presence or absence of visitor's pets in their units. Similar work is also needs to be conducted from the wider perspective of holiday destination managers. In addition, research is required that examines the potential of barriers beyond the lack of provision of appropriate accommodation to the realisation of the potential demand from dog owners to holiday with their pets.

Before advocating or embarking on any expansion of dog-friendly accommodation it is important to recognise the potential impact of such a move on non-dog owning tourists. Whilst it is premature not to allow dogs access to tourism experiences based on justifications lacking research foundations it is equally unacceptable to ignore the views of the non-dog owning tourist population. Consequently, there is a need for analysis of both the impact of pet dogs on the tourism environment and the presence of these animals in the holiday space on non-dog owning tourists' holiday satisfaction. Additionally, it is important to recognise that not all dogs are the same and as a result the dog-owning tourist market should be viewed as a heterogeneous one. In order to determine the nature of this heterogeneity work on the influence of dog breed on owners' holiday desires and experiences could be beneficial in terms of identifying niche markets within the dog owning population.

Research is also required to assess the extent to which the views of dog-owners and the extent of the provision of pet-friendly tourism accommodation in Australia, as shown in this paper, is replicated in other countries. The need for such a study is based on the acknowledgement that personal, public, and tourism industry opinions of dogs and their positioning in the holiday experience may differ around the world based on broad national cultural/social values. Further research is also required to assess the potential 
link between distance travelled and frequency with which dogs are taken on holiday with their owners noted in this paper. This should include an assessment of whether airline policies about the presence of pets on planes inhibit owners from taking their dogs on long-distance holidays.

\section{References}

Anderson, W. P., Reid, C. M. and Jennings, G. L. (1992) 'Pet ownership and risk factors for cardiovascular disease', Medical Journal of Australia, 157, 298-301. Bauman, A. E Schroeder, J. R Furber, S. E and Dobson, A. J. (2001) 'The epidemiology of dog walking: an unmet need for human and canine health', Medical Journal of Australia, 175, 11-12, 632-634.

Beck, A. and Katcher, A. (2003) 'Future directions in human-animal bond research', American Behavioral Scientist, 47, 1, 79 - 93.

Blackshaw, J. K. and Marriott, J. (1995) 'Public open spaces and dogs: a design and management guide for open space professionals and local government', Harlock Jackson Pty Ltd Planning and Development Consultants, Hawthorn East, Australia. Canadian Tourism Commission, (2003) 'Pets can stay Canada opens door to niche market for accommodation providers nationwide', http://www.canadatourism.com/ctx/app/en/ca/pressItem.do? articleId $=49232$ \&language $=$ english.

Carr, N. (2003) 'Use and trust of tourism information sources amongst university students', in Ritchie, B. Carr, N. and Cooper, C. (eds) 'Managing Educational Tourism', Channel View Publications, Clevedon, pp. 215-220 
CNN, (2006) 'The real poop: A dog-friendly B\&B', http://www.cnn.com/2006/US/04/25/otr.pawhouse/index.html.

Csanyi, V. (2005) 'If dogs could talk: Exploring the canine mind', North Point Press, New York.

Curtin, S. (2005) 'Nature, wild animals and tourism: An experiential view', Journal of Ecotourism, 4, 1, $1-15$.

Dennis, S. (2000) 'Holidaying with dogs' (6 ${ }^{\text {th }}$ ed), 'Life. Be in it' Special Projects Unit, Melbourne.

Denniss, R. (2004) 'Overconsumption of pet food in Australia', The Australia Institute, Manuka, ACT.

Doggy Holiday. (2005) 'Doggy holiday: Take your dog with you on holiday’, http://www.doggyholiday.com dogs4sale.com.au. (2005) 'Holiday with dogs', http://www.dogs4sale.com.au/Holiday_with_Dogs.htm Dogsindepth.com. (2007) 'Dogs breed size chart', http://www.dogsindepth.com/dog_breed_size_chart.html Frohlich, R. (2002) 'The ski industry discovers puppy love. Ski Area Management', 41, $4,42-43$.

Golding, C. (1999) 'A hotelier's best friend? Caterer and Hotelkeeper', 188, 28, 30-31. Hall, C. M. and Page, S. (2002) 'The geography of tourism and recreation: Environment, place and space' (2nd ed), Routledge, London. Hartmann, R. (1988) 'Combining field methods in tourism research', Annals of Tourism Research, 15, 1, 88 - 105. 
Headey, B. (1998) 'Do pet owners enjoy better health? Results from the German socioeconomic panel', http://www.petnet.com.au/headey.html.

Henley, J. (2003) 'Luxury hotel serves up dog's dinner', The Guardian, http://www.guardian.co.uk/international/story/0,3604,1033181,00.html.

Holidaying With Dogs. (2005) 'Dog friendly places to stay’, http://www.holidayingwithdogs.com.au/dog_accommodation.htm

Horner, S. and Swarbrooke, J. (1996) 'Marketing tourism, hospitality and leisure in Europe', Thomson Business Press, London.

Hotel Online. (2003) 'The Sheraton, Westin, and W Hotel brands drop restrictions for dogs; Starwood survey convinces chain to include market niche of 62 million U.S. dog owners', http://www.hotelonline.com/News/PR2003_3rd/Aug03_HOTdogs.html. Hughes, M., Newsome, D. and MacBeth, J. (2005) 'Case Study: Visitor Perceptions of Captive Wildlife Tourism in a Western Australian Natural Setting', Journal of Ecotourism, 4, 2, $73-91$.

IHT/Asahi. (2006) 'Up market Osaka hotel menu gone to the dogs', http://www.asahi.com/english/Herald-asahi/TKY200609050108.html. Jennings, G. (2001) ‘Tourism research', John Wiley \& Sons, Milton, Australia. Kimel, E. (2003) 'Hotspots for dog-watching; Dog parks forge a common bond between people, says the author of a canine recreation guide', Sarasota Herald-Tribune. October 9. BV1.

McGill, R. (ed) (2002) ‘Australian dogs on holiday’ (4 ${ }^{\text {th }}$ ed), K \& L Gilkes Pty Ltd, Denistone East, Australia.

McHarg, M., Baldock, C., Heady, C., and Robinson, A. (1995) 'National people and pets' survey', Urban Animal Management Coalition, Sydney. 
Mainini, B., Neuhaus, P. and Ingold, P. (1993) 'Behaviour of marmots Marmota marmota under the influence of different hiking activities', Biological Conservation, 64, $161-164$

Meddaugh, S. (1994) 'Martha calling', Houghton Mifflin Company, Boston. Messent, P. (1983) 'Social facilitation of contact with other people by pet dogs', in Katcher, A. H. and Beck, A. (eds) 'New perspectives on our lives with companion animals', University of Pennsylvania Press, Philadelphia, pp. $37-46$.

Miller, R. (2006) 'The 2007 Leisure market research handbook', Richard K. Miller \& Associates, Loganville, GA.

Newton, P. (1999) 'Passports for pets trial is launched', The Telegraph, http://www.telegraph.co.uk/et? $\mathrm{ac}=002549632124328 \& \mathrm{rtmo}=\mathrm{LShNlKbd \& atmo}=\mathrm{rrrrrrq} \& p g=/ \mathrm{et} / 99 / 8 / 3 / \mathrm{npet} 03 . \mathrm{html}$. Pet Food Institute. (2006) 'Dog \& cat ownership in U.S. by household’, http://www.petfoodinstitute.org/reference_pet_data.cfm Petnet.com. (2007) 'Value of the pet industry', http://www.petnet.com.au/power/value.html Petnet.com. (2003) 'Pet ownership in Australia', http://www.petnet.com.au/statistics.html Petnet.com. (2000a) 'Pets: The key to elderly health and happiness', http://petnet.com.au/releases/24081998.html.

Petnet.com (2000b) '14\% of Australians always travel with their "best friends", http://petnet.com.au/releases/15062000.html Pets Playground (2005) 'Pet friendly holidays', http://petsplayground.com.au/ 
Racher, J. (2005) 'Travelling with dogs: Are dog-friendly hotels in Canada meeting the needs of dogs and their owners?' Unpublished Honours thesis, Brock University Rogers, J and Hart, L. A. (1993) 'The role of pet dogs in casual conversations of elderly adults', Journal of Social Psychology, 133, 3, 265 - 278.

Sakakeeny, K. (2004) 'Where do sleeping dogs lie?' www.eturbonews.com/news/23JAN2004/text.htm. Salmon, P. W. and Salmon, I. M. (1983) 'Who owns who? Psychological research into the human-pet bond in Australia', in Katcher, A. H. and Beck, A. (eds) 'New perspectives on our lives with companion animals', University of Pennsylvania Press, Philadelphia, pp. $244-265$.

Swarbrooke, J. and Horner, S. (1999) 'Consumer behaviour is tourism', Butterworth Heinemann, Oxford.

TakeAbreak.com.au. (2005) 'Holidaying with Pets', http://www.takeabreak.com.au/HolidayingwithPets.htm Torkildsen, G. (1999) 'Leisure and recreation management' (4th ed.), E\&FN Spon, London.

Travelwire News (2005) 'Luxury travel \& vacations have gone to the dogs', http://www.travelwirenews.com/cgi-script/csArticles/articles/000038/003833.htm Veal, A. and Lynch, R. (2001) ‘Australian leisure’ ( $2^{\text {nd }}$ ed), Longman, Frenchs Forest. 
Figure 1

Trend in number of households owning at least one dog in the USA

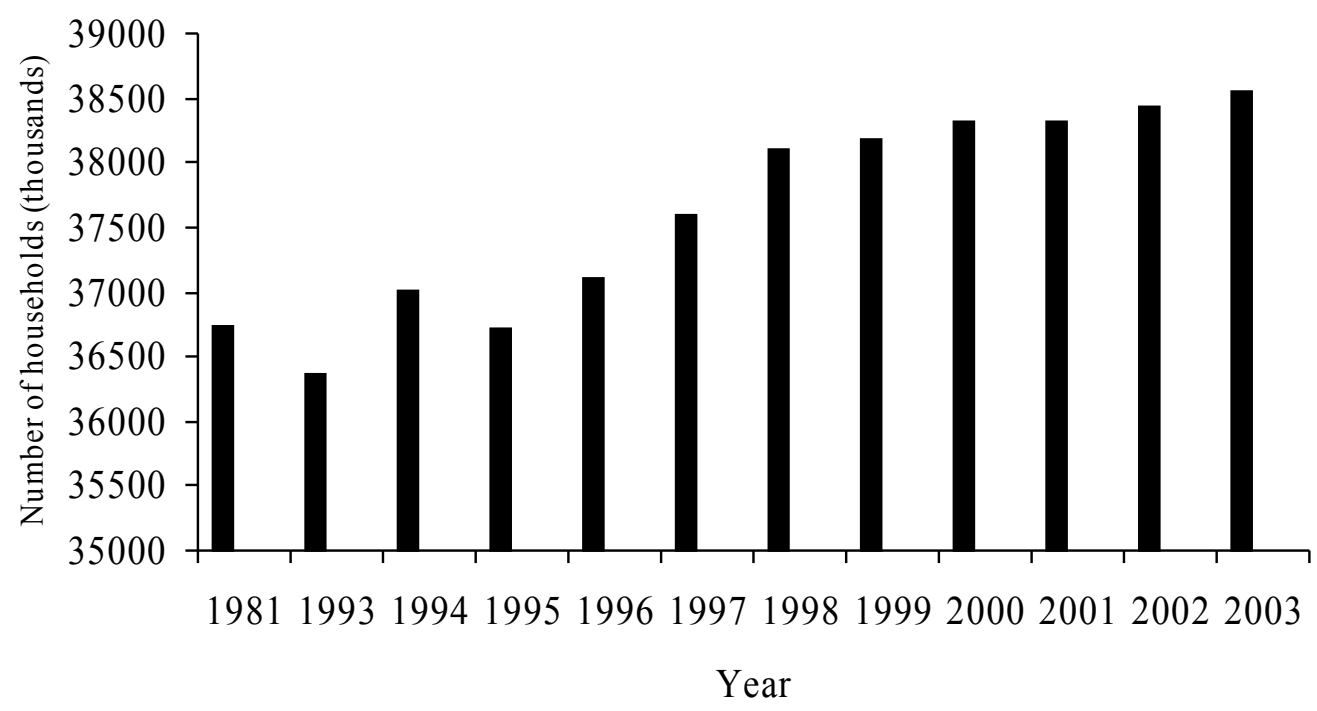

(Pet Food Institute, 2006) 
Table 1

\begin{tabular}{|c|c|c|c|c|c|c|c|}
\hline & aracteristics & of respo & $\begin{array}{l}\text { Table } \\
\text { dents anc }\end{array}$ & their dos & $(\%$ of res & ondents) & \\
\hline Annual & & 35,001 & 50,001 & 65,001 & 80,001 & 100,001 & More \\
\hline Household & & - & - & - & - & - & than \\
\hline income & & 50,000 & 65,000 & 80,000 & 100,000 & 150,000 & 150,000 \\
\hline$(\mathrm{AUS} \$)(\mathrm{n}=$ & 9.8 & 16.0 & 16.4 & 16.0 & 18.6 & 13.8 & 9.5 \\
\hline 275) & & & & & & & \\
\hline Years of & & & & 16 and & & & \\
\hline $\operatorname{dog}$ & $0-1$ & $1-5$ & $6-15$ & over & & & \\
\hline ownership & 12.3 & 28.8 & 22.9 & 36.1 & & & \\
\hline$(\mathrm{n}=302($ & & & & & & & \\
\hline Age of & 25 and & $26-$ & 46 and & & & & \\
\hline respondent & under & 45 & over & & & & \\
\hline (years) $n=$ & 12.5 & 59.3 & 28.1 & & & & \\
\hline & & & & & & & \\
\hline Height of & & & 22 and & & & & \\
\hline dog (inches) & $0-14$ & $15-21$ & above & & & & \\
\hline$(\mathrm{n}=278)$ & 21.2 & 36.0 & 42.8 & & & & \\
\hline Marital & Married/c & & & & & & \\
\hline status $(\mathrm{n}=$ & o-habiting & Single & & & & & \\
\hline 301) & 68.8 & 31.2 & & & & & \\
\hline Children in & Yes & No & & & & & \\
\hline household & 30.2 & 69.8 & & & & & \\
\hline$(\mathrm{n}=298)$ & & & & & & & \\
\hline
\end{tabular}


Table 2

Reasons why dog owners would prefer to take their pets on holiday with them

\begin{tabular}{|l|c|}
\hline \multicolumn{1}{|c|}{ Reasons } & Number of respondents \\
\hline Dog is part of the family & 110 \\
\hline Helps us relax and makes holiday more pleasurable & 52 \\
\hline Enjoy companionship of dog & 51 \\
\hline Avoid feelings of guilt at leaving dog behind & 18 \\
\hline Encourages me/us to exercise & 11 \\
\hline Love my/our dog & 7 \\
\hline Feel safer if dog is with me/us & 5 \\
\hline Cheaper/more convenient to take dog on holiday & 3 \\
than leave it behind & \\
\hline Make the dog happy & 39 \\
\hline Avoid dog feeling depressed or anxious & 15 \\
\hline
\end{tabular}

Note: Respondents sometimes gave more than one reason for wishing to take their dog on holiday with them, whilst some

respondents gave no answer when asked why they would like to do this 


\begin{tabular}{|c|c|c|c|c|c|c|}
\hline Holic & y behaviour $\mathrm{c}$ & $\begin{array}{r}\text { Table } 3 \\
\text { dog owners }\end{array}$ & etween & 999 and & 004 & \\
\hline \multirow[t]{2}{*}{$\begin{array}{l}\text { Holiday } \\
\text { destination }\end{array}$} & \multirow{2}{*}{$\begin{array}{l}\text { Number of } \\
\text { Holidays } \\
\text { taken }\end{array}$} & \multicolumn{5}{|c|}{$\begin{array}{l}\text { Frequency of holidays taken with pet dogs (\% of } \\
\text { respondents) }\end{array}$} \\
\hline & & $\begin{array}{c}1 \\
\text { (Always) }\end{array}$ & $\begin{array}{c}2 \\
(3 / 4 \\
\text { time }) \\
\end{array}$ & $\begin{array}{c}3 \\
\text { (Half } \\
\text { time) } \\
\end{array}$ & $\begin{array}{c}4 \\
(1 / 4 \\
\text { time }) \\
\end{array}$ & $\begin{array}{c}5 \\
\text { (Never) }\end{array}$ \\
\hline Queensland & 1501 & 25.7 & 13.6 & 17.6 & 15.1 & 27.9 \\
\hline New South Wales & 515 & 9.7 & 4.3 & 6.5 & 7.0 & 72.6 \\
\hline Victoria & 168 & 8.6 & 0.9 & 1.7 & 4.3 & 84.5 \\
\hline Tasmania & 19 & 1.4 & 0.0 & 0.0 & 1.4 & 97.1 \\
\hline Western Australia & 40 & 3.8 & 2.5 & 1.3 & 5.1 & 87.3 \\
\hline Northern Territory & 16 & 1.5 & 1.5 & 0.0 & 3.1 & 93.8 \\
\hline $\begin{array}{l}\text { Outside of } \\
\text { Australia }\end{array}$ & 253 & 2.9 & 0.7 & 0.7 & 2.9 & 92.6 \\
\hline
\end{tabular}




\begin{tabular}{|l|c|c|c|c|c|}
\hline \multicolumn{6}{|c|}{ Table 4} \\
Frequency of holidays taken with pet dogs in Queensland between 1999 and 2004 \\
\multicolumn{7}{|c|}{ divided by marital status (\% of respondents) } \\
\hline Marital status & 1 & 2 & 3 & 4 & 5 (Never) \\
& (Always) & $(3 / 4$ time) & (Half time) & $(1 / 4$ time) & \\
\hline Married/co- & 20.3 & 14.3 & 15.4 & 19.2 & 30.8 \\
habiting & & & & & \\
\hline Single & 37.0 & 11.1 & 22.2 & 7.4 & 22.2 \\
\hline
\end{tabular}

\begin{tabular}{|l|c|c|c|c|c|}
\hline \multicolumn{7}{|c|}{ Table 5} \\
\multicolumn{7}{|c|}{ Frequency of holidays taken with pet dogs in Queensland between 1999 and 2004} \\
\\
\multicolumn{1}{|c|}{ divided by owners' age (\% of respondents) } \\
\hline Age group (years) & 1 & 2 & 3 & 4 & 5 (Never) \\
& & & & & \\
\hline 25 and under & 41.2 & 14.7 & 17.7 & 5.9 & 20.6 \\
\hline $26-45$ & 19.3 & 13.3 & 22.0 & 20.7 & 24.7 \\
\hline 46 and over & 30.7 & 9.3 & 8.0 & 10.7 & 41.3 \\
\hline
\end{tabular}




\begin{tabular}{|l|c|c|c|c|c|c|c|}
\hline \multicolumn{7}{|c|}{ Table 6} \\
\hline \multirow{2}{*}{$\begin{array}{l}\text { Type of } \\
\text { accommodation }\end{array}$} & $\begin{array}{c}\text { Ease (Very } \\
\text { easy) }\end{array}$ & 2 & 3 & 4 & 5 & 6 & $\begin{array}{c}\text { (Extremely } \\
\text { hard) }\end{array}$ \\
\cline { 2 - 8 } $\begin{array}{l}\text { Rural/farm } \\
\text { based } \\
(\mathrm{n}=163)\end{array}$ & 17.8 & 9.2 & 14.7 & 11.0 & 10.4 & 9.2 & 27.6 \\
\hline $\begin{array}{l}\text { Beach side } \\
(\mathrm{n}=197)\end{array}$ & 15.2 & 4.1 & 10.7 & 10.2 & 12.2 & 13.2 & 34.5 \\
\hline $\begin{array}{l}\text { Urban/city } \\
(\mathrm{n}=136)\end{array}$ & 8.8 & 3.7 & 4.4 & 13.2 & 10.3 & 10.3 & 49.3 \\
\hline $\begin{array}{l}\text { Campsites } \\
(\mathrm{n}=163)\end{array}$ & 9.2 & 8.6 & 8.6 & 17.2 & 16.0 & 11.7 & 28.8 \\
\hline $\begin{array}{l}\text { Self catering } \\
(\mathrm{n}=140)\end{array}$ & 5.7 & 2.1 & 5.7 & 20.0 & 15.7 & 12.1 & 38.6 \\
\hline $\begin{array}{l}\text { Catered } \\
(\mathrm{n}=116)\end{array}$ & 4.3 & 0.9 & 0.9 & 15.5 & 15.5 & 12.9 & 50.0 \\
\hline $\begin{array}{l}\text { Budget } \\
(\mathrm{n}=131)\end{array}$ & 3.1 & 5.3 & 7.6 & 16.0 & 13.0 & 14.5 & 40.5 \\
\hline $\begin{array}{l}\text { Mid - price } \\
\text { range } \\
(\mathrm{n}=133)\end{array}$ & 3.0 & 3.8 & 11.3 & 17.3 & 15.0 & 45.9 \\
\hline $\begin{array}{l}\text { Luxury (n } \\
97)\end{array}$ & 2.1 & 1.0 & 1.0 & 7.2 & 8.3 & 16.4 & 63.9 \\
\hline
\end{tabular}




\begin{tabular}{|c|c|c|c|c|c|}
\hline Sources of information & $\begin{array}{r}\text { used to locate do } \\
\text { of res }\end{array}$ & $\begin{array}{l}\text { le } 7 \\
\text { friend } \\
\text { ndent }\end{array}$ & holid & ccomn & dation units $(\%$ \\
\hline & 1 (Very useful) & 2 & 3 & 4 & 5 (No use at all) \\
\hline Friends $(n=262)$ & 48.5 & 23.7 & 14.5 & 5.3 & 8.0 \\
\hline Relatives $(\mathrm{n}=251)$ & 27.9 & 19.1 & 19.9 & 11.6 & 21.5 \\
\hline $\begin{array}{l}\text { Travel agents }(\mathrm{n}= \\
\text { 229) }\end{array}$ & 4.4 & 10.9 & 25.3 & 19.7 & 39.7 \\
\hline $\begin{array}{l}\text { Tourist information } \\
\text { centres }(n=238)\end{array}$ & 10.1 & 14.7 & 32.4 & 17.2 & 25.6 \\
\hline $\begin{array}{l}\text { Television/radio }(\mathrm{n}= \\
241)\end{array}$ & 5.0 & 7.5 & 21.6 & 27.4 & 38.6 \\
\hline $\begin{array}{l}\text { Newspaper/magazines } \\
(\mathrm{n}=243)\end{array}$ & 7.8 & 13.6 & 28.0 & 19.8 & 30.9 \\
\hline The Internet $(\mathrm{n}=246)$ & 39.0 & 24.8 & 17.1 & 6.9 & 12.2 \\
\hline $\begin{array}{l}\text { The government/local } \\
\text { councils }(\mathrm{n}=251)\end{array}$ & 27.9 & 30.3 & 21.5 & 8.4 & 12.0 \\
\hline
\end{tabular}




\begin{tabular}{|c|c|c|c|c|c|}
\hline $\mathrm{Ne}$ & otiation of ho & desir & 8 & resen & $\operatorname{dogs}$ \\
\hline & Level of 'co & mise' & piness & mprom & of respondents) \\
\hline & 1 (Totally) & 2 & 3 & 4 & 5 (Not at all) \\
\hline $\begin{array}{l}\text { Have to } \\
\text { compromise } \\
(\mathrm{n}=281)\end{array}$ & 16.7 & 28.8 & 27.1 & 10.3 & 17.1 \\
\hline $\begin{array}{l}\text { Happy to } \\
\text { compromise } \\
(\mathrm{n}=278)\end{array}$ & 21.6 & 21.6 & 31.3 & 13.3 & 12.2 \\
\hline
\end{tabular}

Figure 2

Willingness of owners to pay for dog friendly holidays as a percentage of the cost of non-dog friendly holidays taken

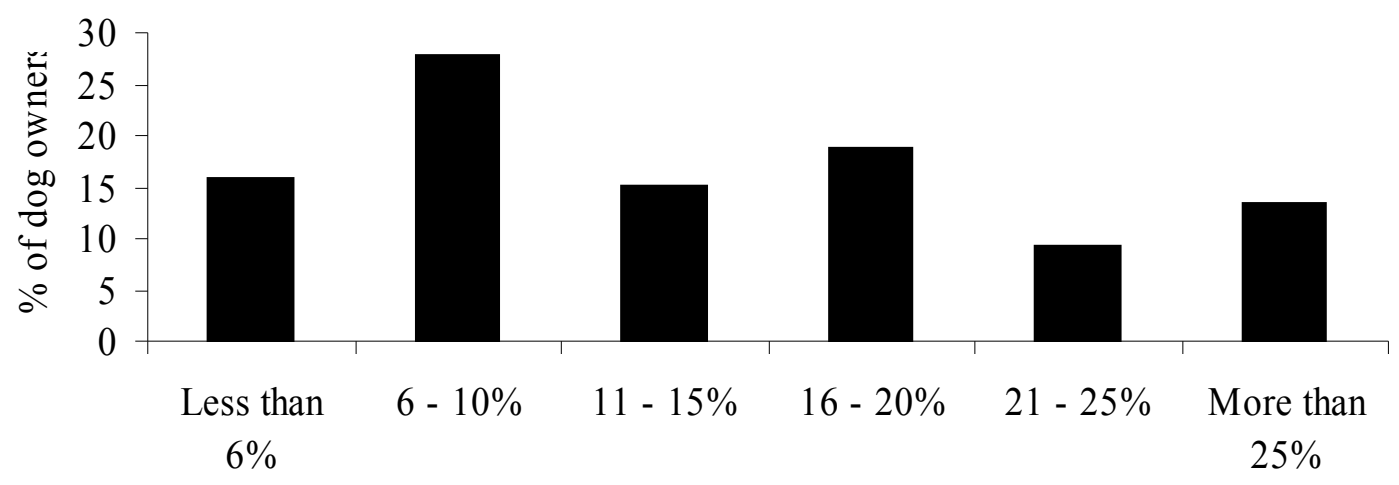

Extra percentage that owners are willing to pay 